\title{
KNOWLEDGE, ATTITUDE AND PRACTICE OF HEALTH CARE PROFESSIONALS REGARDING PHARMACOVIGILANCE IN SOUTH-SOUTH NIGERIA
}

\author{
${ }^{1,6}$ Opadeyi AO, ${ }^{2,3,4}$ Fourrier-Réglat $\mathrm{A},{ }^{1,5,6} \mathrm{Isah} \mathrm{AO}$
}

${ }^{1}$ Department of Clinical Pharmacology and Therapeutics, University of Benin,

Benin-City, Edo State, Nigeria. ${ }^{2}$ Univ. Bordeaux, Inserm, Bordeaux Population Health Research

Centre, team Pharmacoepidemiology, UMR 1219, F-33000 Bordeaux, France. ${ }^{3} \mathrm{CHU}$ Bordeaux, Service de Pharmacologie Médicale, F-33000 Bordeaux, France.

${ }^{4}$ CIC Bordeaux CIC1401, F-33000 Bordeaux, France

${ }^{5}$ Chairman, National Drug Safety Advisory Committee National Agency for Food and Drug

Administration and Control, Federal Ministry of Health. Abuja, Nigeria.

${ }^{6}$ Department of Medicine, University of Benin Teaching Hospital, Benin-City, Edo State, Nigeria.

Correspondence and reprint request to: Dr Opadeyi AO. Department of Clinical Pharmacology and Therapeutics, University of Benin, Benin-City, Edo State, Nigeria.

Email: felabimbola@yahoo.com |_Phone:+2348037075435

\begin{abstract}
Background: In Nigeria, reporting pharmacovigilance issues including adverse drug reactions (ADRs) from health facilities is encouraged especially by health care professionals (HCPs). Objectives: This study assessed the knowledge, attitude and practice of HCPs regarding pharmacovigilance in teaching hospitals in the South-South geo-political zone of Nigeria. Methodology: A cross-sectional study was conducted in six selected teaching hospitals in the South-South zone of Nigeria. A semi-structured questionnaire was self-administered to 1200 HCPs (doctors, pharmacists and nurses). Information sought included demographics, knowledge, attitude and practice of pharmacovigilance especially ADRs reporting. The data was analysed using descriptive and inferential statistics. Results: The 796 adequately completed questionnaires were used for the analysis. The mean age (standard deviation, SD) of the participants was 39.0 (8.0) years and the mean duration of practice (SD) was 12.7 (8.2) years. Two hundred and forty-one (30.3 \%) of HCPs had ever documented or reported ADRs, of which only $97(40.2 \%)$ had ever used the national ADRs reporting form. Most respondents 746 (93.7 \%) knew they could submit ADRs reports relating to new medicines and submit reports of new and unexpected ADRs 683 (85.8\%). Fewer respondents 540 (67.3\%) would submit reports relating to herbal medicines, and 256 (32.2 \%) mild ADRs. Four hundred and fifty-six (57.3 \%) had no difficulty in determining whether to report ADRs. Overall, nurses appeared the least knowledgeable about reporting ADRs. On improving reports, 278 (34.9\%) respondents advocated increased awareness and education on ADRs reporting. Conclusion: The HCPs in tertiary hospitals in the South-South zone had a modest knowledge, positive attitude but poor reporting practices in pharmacovigilance which may be improved with education and easier reporting processes.
\end{abstract}

Key words: Adverse drug reaction reporting, Attitudes, Health care professionals, Health knowledge, Nigeria, Pharmacovigilance, Practice

\section{INTRODUCTION}

The World Health Organisation (WHO) defines Pharmacovigilance as "the science and activities

Access this article online

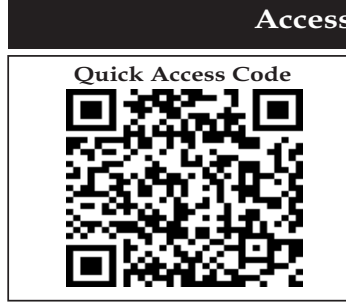

WEBSITE: www.kjmsmedicaljournal.com

DOI: $10.36020 / \mathrm{kjms} .2021 .1501 .007$ relating to the detection, assessment, understanding and prevention of adverse effects or any other possible drugrelated problems". ${ }^{1}$ The scope of pharmacovigilance has been widened to include other relevant issues such as medication errors, lack of effectiveness, abuse, and irrational use of medicine whilst the product concerns include herbals, complementary 
medicines, vaccines, and biologicals. ${ }^{1}$ Early detection, reporting of adverse drug reactions (ADRs) remain key elements to the growth of pharmacovigilance. ${ }^{2}$ Spontaneous reporting of ADRs is the most accessible method of pharmacovigilance to health care professionals (HCPs). The number of ADRs reports has grown remarkably with over 18 million Individual Case Safety Reports (ICSRs) in the WHO database as of February 2018. ${ }^{3}$ However, the numbers of ADRs reported from low and lower-middle-income countries remains sub-optimal despite the improvement in reported ADRs. ${ }^{3-5}$ Factors that have been identified to contribute to ADRs underreporting include ignorance of types of ADRs that should be reported, hesitancy, lethargy about reporting, lack of adequate information about recently marketed medicines, difficulty in obtaining ADRs reporting form as well as the bureaucratic process in reporting. ${ }^{6-8}$

The rate of reporting of ADRs is quite low in Nigeria. The National Pharmacovigilance Centre (NPC) of Nigeria has just over 18,000 ADR reports in its database since its inception in 2004 despite the implementation of active pharmacovigilance system. ${ }^{8}$ Studies evaluating the knowledge, attitude and practices (KAP) of Nigerian HCPs towards reporting ADRs had shown that lack of awareness and non-availability of the national ADR reporting forms (Yellow forms), cumbersome reporting processes, lack of knowledge of the location of reporting centres and insufficient knowledge of who can report were some of the factors that might have contributed to underreporting. ${ }^{9-12}$ Other factors include fear of litigation, lack of adequate time, and failure to identify ADRs. ${ }^{13,14}$

These earlier studies from single institutions in other geo-political zones in the country focused mainly on reporting ADRs and only a few on the knowledge of the HCPs in reporting the expanded product concerns. Though, there is a high use of herbal medicines, unrestricted use of prescriptiononly medicines, fatal occurrences associated with substandard and falsified medical products use, and a high burden (though not properly quantified) of ADRs contributing to the burden of medicinesrelated problems in Nigeria., ${ }^{8,15}$ The studies showed varied knowledge of types of ADRs ranging from $62 \%-90 \%$ and an even lower knowledge of the ADR reporting process between $13 \%-39 \%{ }^{9-11,13,17}$ A KAP study involving a state in the South-South zone also showed that although doctors observed ADRs, only $7.3 \%$ of all ADRs reports had been sent to the NPC from both study sites. ${ }^{18}$ Most of these studies were carried out among doctors and very few on nurses and hospital pharmacists despite that all HCPs can report ADRs in Nigeria. ${ }^{19}$

To enhance reports and improve communication with the NPC, Zonal Pharmacovigilance Centres were created in 2012 (including the South-South Zonal Pharmacovigilance Centre, SSZPC). Therefore, this study was conducted to determine the KAP of the HCPs in the South-South zone towards pharmacovigilance (including the knowledge of the expanded scope and products concerns) and also to determine the awareness level of the HCPs regarding the SSZPC.

\section{MATERIALS AND METHODS}

Study setting and design: A cross-sectional study was carried out in January to March 2016 in the South-South geo-political zone of Nigeria. The zone has six states which are: Akwa-Ibom, Bayelsa, Cross Rivers, Delta, Edo and Rivers States and a population of 28,829,288 million persons as at 2016 $(\mathrm{NPC} / \mathrm{NBC}, 2016)^{20}$

Eligibility criteria: Teaching hospitals were selected for the study as they were training institutions for undergraduates and post-graduates. They also offer sub-speciality services and have a varied clientele base. The South-South zone has a total of eight teaching hospitals with three located in a state and other states having one teaching hospital each. The state with three teaching hospitals had one teaching hospital randomly selected using a table of random numbers.

Thus, the study was carried out in University of Benin Teaching Hospital (UBTH), Benin-City, Edo State; Delta State University Teaching Hospital (DELSUTH), Oghara, Delta State; Niger Delta University Teaching Hospital (NDUTH), Okolobri, Bayelsa State; University of Port Harcourt Teaching Hospital (UPTH), Port Harcourt, Rivers State; University of Uyo Teaching Hospital (UUTH), Uyo, Akwa-Ibom State and University of Calabar Teaching Hospital (UCTH), Calabar, Cross-River State. 


\section{Ethical consideration}

Ethical approval was obtained from the Research and Ethics Committees of all the selected health institutions: DELSUTH Health Research Ethics Committee (DELSUTH/HREC/2015/024 issued on the $27^{\text {th }}$ August 2015); NDUTH Research and Ethics Committee (NDUTH/REC/0005/2015 issued on $7^{\text {th }}$ September 2015); UBTH Ethics and $\mathrm{R}$ e s e a $\mathrm{rch}$

C o m m i t t e e (UBTH/ADM/E22/2/VOL.VII/1245 issued on $17^{\text {th }}$ August 2015); UCTH Health Research Ethics Committee (UCTH/HREC/33/360 issued on $14^{\text {th }}$ August 2015); UPTH Hospital Ethical Committee (UPTH/ADM/90/S.II/VOL.X/668 issued on $29^{\text {th }}$ June 2015) and UUTH Institutional Health Research $\mathrm{E} \mathrm{t} \mathrm{h}$ i $\mathrm{c}$ a 1 $\mathrm{C}$ o $\mathrm{m} \mathrm{m}$ i t t e e (UUTH/AD/S/96/VOL.XIV/357 issued on $13^{\text {th }}$ November 2015). Written informed consent was obtained from all participants. The participants were assured of the confidentiality of their responses. Further institutional approval was obtained from the Chief Medical Director/Hospital Management before inclusion in the study.

Study population: HCPs in the six selected institutions involved in patient care and in a position to report ADRs, namely doctors, pharmacists, and nurses, were invited to participate in the study. Only post-registration HCPs were included in the study as the study measured the practice in the previous year. The approximate number of post-registration HCPs working in the selected hospitals as at January 2016 was 4912 with 2085 doctors (42.4\%), 2662 nurses (54.2\%), and 165 pharmacists (3.4\%).

The sample size was estimated using Epi Info TM version 7 software (Centre for Disease Control) sample size comparing two proportions ${ }^{21}$, as this was a pre-educational intervention survey. A previous study had shown that $26 \%$ of HCPs used the national ADR form to report ADRs ${ }^{10}$, therefore, considering a power of $80 \%$ and a $5 \%$ significance level and aiming for an improvement where $40 \%$ of HCP would report ADRs with the national ADR form after the intervention, the estimated sample size for this survey was 356 . Furthermore, with an anticipated $15 \%$ non-response rate, the minimum sample size was 410 respondents. However, to increase statistical power, a total of 1200 questionnaires were distributed to the various centers.
All HCPs who met the criteria were contacted through their respective institutional heads and Heads of Department. Subsequently, consenting HCPs were enrolled sequentially in the study. Those who could not complete the questionnaire were treated as non-responders and were not included in the final analysis.

Data collection: The selected hospitals were proportionately sampled and, in each hospital, the HCPs were stratified by profession and conveniently sampled.

The questionnaire developed after searching the literature in previous studies. . $9-11,13,14,22^{-}$ ${ }^{24}$ contained questions on demographics of the HCPs including age, gender, duration of practice, and institution. Twelve questions were asked about knowledge of pharmacovigilance, including ADRs definitions, reporting schemes, location of pharmacovigilance centre, and the factors that may affect reporting. In addition, ten questions relating to attitude towards pharmacovigilance were asked. Lastly, 18 questions regarding their practice of ADRs reporting, including if they had ever used the national ADR reporting form as well as previous pharmacovigilance training was equally sought.

The questionnaire was pre-tested among $25 \mathrm{HCPs}$ from various hospitals including a few from one of the participating hospitals who were attending a workshop on pharmacovigilance and had the questionnaire administered before the commencement of the workshop. Modifications were made accordingly to the final questionnaire. The participants from the participating hospital and data obtained at the pretest were not included in the main study and analysis. Content and face validity was done for the questionnaire by experts in Clinical Pharmacology and Therapeutics.

\section{Data Analysis}

The WHO definition of ADRs was used and the keywords (noxious and unintended or synonyms) had to be present to be regarded as a correct answer. 25 Partially correct answers may include one or the other and an incorrect answer did not include any 
of the keywords or related synonyms. In determining the correct KAP of pharmacovigilance by the HCPs, the frequency and percentages of correct answers for each question on knowledge, practice and positive attitudes were accepted as appropriate. The various answers from open-ended questions were synthesized thematically and similar answers duly collated. Multiple responses were accepted.

The data were analysed using SPSS (IBM SPSS Statistics for Windows, Version 21.0. Armonk, NY: IBM Corp). The study was analysed descriptively, with means \pm standard deviation (SD) for quantitative variables, and frequencies and percentages for categorical variables.

Categorical variables were analysed inferentially using Chi-square. The possible determinants of ever reporting ADRs using the national ADR reporting form was done using Chi-square and Mann Whitney U test as appropriate. The level of significance was set at $\mathrm{p}<0.05$.

\section{RESULTS}

\section{Demography of the Participating HCPs}

A total of 1200 questionnaires were distributed to HCPs in the various teaching hospitals and 850 were retrieved. However, 39 questionnaires were excluded from the analysis as the respondents did not meet the inclusion criteria and 15 due to incomplete records. A total of 796 respondents were included with a corrected response rate of $67.6 \%$. The mean age (SD) of the participating HCPs was $39.0(8.0)$ years and their mean duration of practice (SD) was 12.7 (8.2) years. The demographic distribution of the HCPs is shown in Table 1.

Among the study respondents, only $15.8 \%$ had received any training in ADRs reporting. Of these, pharmacists were more likely to have been trained in pharmacovigilance and ADRs reporting (Fisher's exact test $=85.1, \mathrm{p}=<0.001$ ).

\section{Knowledge of the HCPs in South-south Nigeria regarding pharmacovigilance}

One hundred and sixty-nine respondents (21.2 \%) provided the correct definition of ADRs while 13.1 $\%$ and $53.4 \%$ of respondents gave incorrect or partially correct definitions respectively.
Pharmacists were the HCPs cadre with the highest proportion of correct definition of ADRs (46.3\%). (Table 2).

Regarding the characteristics of ADRs, most respondents $(82.0 \%)$ knew that ADRs could result from the pharmacological action of the drug but only $35.7 \%$ knew that ADRs occurrence could be delayed. Furthermore, the majority of respondents $(93.7 \%)$ knew that ADRs could occur with newly marketed medicines and $63.9 \%$ of the HCPs felt life-threatening ADRs should be reported. Between $55.4 \%$ and $60.7 \%$ of respondents knew that cases of medication errors, drug abuse or dependence should be reported. However, only $32.2 \%$ felt there was a need to report mild ADRs. Overall, the proportion of nurses with adequate knowledge of product concerns and types of ADRs was low (Table 2).

Most HCPs felt that doctors (92.7\%), pharmacists $(90.8 \%)$ and nurses $(89.8 \%)$ should be able to report ADRs (multiple responses were accepted). On ranking the responses per cadre of HCPs, each cadre believed their profession could be the primary reporter compared with others- $99.2 \%$ of doctors, $91.3 \%$ of nurses, and $98.8 \%$ of pharmacists. Furthermore, the respondents believed other categories of persons including patients $(16.5 \%)$, any other allied health care worker (5.8 \%), anyone $(5.5 \%)$, or others $(2.9 \%)$ (i.e., laboratory technicians, community health extension workers, traditional medicine dealers, patent medicine dealers) can also report ADRs (Multiple responses were accepted).

There was poor awareness of the pharmacovigilance centres as only $49.7 \%$ were aware of the local pharmacovigilance centre in their institution, and only $22.2 \%$ had ever visited the centre.

More specifically, only $26.6 \%$ of HCPs were aware of the existence of the South-South Zonal Pharmacovigilance Centre. Awareness of the existence of the NPC was reported by $50.8 \%$ of the respondents, of which $33.9 \%$ knew the exact location of the headquarters. Two hundred and eighty $(35.2 \%)$ respondents were aware of the ADR reporting form. Of these, $76.7 \%$ admitted to having seen the form. 
Table 1: Demographics of the Health Care Professionals in six selected teaching hospitals in the South-South zone of Nigeria

\begin{tabular}{lc}
\hline Characteristics & Value (\%) \\
\hline Mean age \pm SD (years) & $38.97 \pm 8.1$ \\
Meanduration of practice \pm SD (years) & $12.66 \pm 8.2$ \\
Gender & \\
Male & $297(37.3)$ \\
Female & $473(59.4)$ \\
Missing & $26(3.3)$ \\
Profession & \\
Doctors & $373(46.9)$ \\
Nurses & $343(43.1)$ \\
Pharmacists & $80(10.1)$ \\
Institutions & \\
DELSUTH & $66(8.3)$ \\
NDUTH & $51(6.4)$ \\
UBTH & $198(24.9)$ \\
UCTH & $179(22.5)$ \\
UPTH & $164(20.6)$ \\
UUTH & $138(17.3)$ \\
\hline
\end{tabular}

Delta State University Teaching Hospital (DELSUTH), Niger Delta University Teaching Hospital (NDUTH), University of Benin Teaching Hospital (UBTH), University of Calabar Teaching Hospital (UCTH),

University of Port-Harcourt Teaching Hospital (UPTH), University of Uyo Teaching Hospital (UUTH)

Table 2: Knowledge of the characteristics of ADRs by Health Care Professionals in the South- South zone of Nigeria

\begin{tabular}{|c|c|c|c|c|c|}
\hline Knowledge items about ADRs & All HCPs & Doctors & Nurses & Pharmacists & p value \\
\hline $\begin{array}{l}\text { Correct definition of ADRs } \\
\text { New and unexpected ADRs } \\
\text { ADRs resulting from normal } \\
\text { ADRs persisting for a long time } \\
\text { ADRs delayed for a long time }\end{array}$ & $\begin{array}{l}169(21.2) \\
683(85.8) \\
653(82.0) \\
474(59.5) \\
284(35.7)\end{array}$ & $\begin{array}{c}91(24.4) \\
352(94.4) \\
337(90.3) \\
273(73.2) \\
187(50.1)\end{array}$ & $\begin{array}{l}41(12.0) \\
255(74.3) \\
253(73.8) \\
140(40.8) \\
56(16.3)\end{array}$ & $\begin{array}{l}37(46.3) \\
76(95.0) \\
63(78.8) \\
61(76.3) \\
41(51.3)\end{array}$ & $\begin{array}{l}<0.001 \\
<0.001 \\
<0.001 \\
<0.001 \\
<0.001\end{array}$ \\
\hline $\begin{array}{l}\text { ADRs occurring as follows: } \\
\text { a newly marketed medicine } \\
\text { an established medicine } \\
\text { a vaccine } \\
\text { over the counter preparations } \\
\text { medicine used by children } \\
\text { a biological medicine } \\
\text { an herbal medicine } \\
\text { a complementary medicine } \\
\text { at the end of use of medicines }\end{array}$ & $\begin{array}{l}746(93.7) \\
663(83.3) \\
644(80.9) \\
625(78.5) \\
598(75.1) \\
552(69.3) \\
540(67.8) \\
539(67.7) \\
458(57.5)\end{array}$ & $\begin{array}{l}367(98.4) \\
351(94.1) \\
353(94.6) \\
336(90.1) \\
340(91.2) \\
319(85.5) \\
297(79.6) \\
302(81.0) \\
230(61.7)\end{array}$ & $\begin{array}{l}301(87.8) \\
234(68.2) \\
217(63.3) \\
218(63.6) \\
192(56.0) \\
159(46.4) \\
173(50.4) \\
168(49.0) \\
182(53.1)\end{array}$ & $\begin{array}{l}78(97.5) \\
78(97.5) \\
74(92.5) \\
71(88.8) \\
66(82.5) \\
74(92.5) \\
70(87.5) \\
69(86.3) \\
46(57.5)\end{array}$ & $\begin{array}{l}<0.001 \\
<0.001 \\
<0.001 \\
<0.001 \\
<0.001 \\
<0.001 \\
<0.001 \\
<0.001 \\
0067\end{array}$ \\
\hline $\begin{array}{l}\text { Medicines misused or used in error } \\
\text { Report cases of drug abuse } \\
\text { Report cases of drug dependence } \\
\text { Report mild ADRs } \\
\text { Report life threatening ADRs }\end{array}$ & $\begin{array}{l}483(60.7) \\
441(55.5) \\
454(57.0) \\
256(32.2) \\
509(63.9)\end{array}$ & $\begin{array}{l}240(64.3) \\
227(60.9) \\
239(64.1) \\
111(29.8) \\
177(47.5)^{*}\end{array}$ & $\begin{array}{l}187(54.5) \\
167(49.0) \\
168(49.1) \\
101(29.4) \\
275(80.2)\end{array}$ & $\begin{array}{l}56(70.0) \\
47(58.8) \\
47(58.8) \\
44(55.0) \\
57(71.3)\end{array}$ & $\begin{array}{c}0.005 \\
0.005 \\
<0.001 \\
<0.001 \\
<0.001\end{array}$ \\
\hline
\end{tabular}

ADRs: Adverse Drug Reactions, P value from Pearson chi square test and Fisher's exact test 


\section{Attitudes toward reporting of ADRs}

Most respondents (92.3\%) believed they should report all ADRs, that it was their professional obligation to report $(92.1 \%)$ and about half $(56.9 \%)$ of the HCPs believed they had no difficulty in determining if an ADRs had occurred in a patient. Nurses appeared to have a lower proportion of positive attitudes (Table3).

Table 3: Attitude of Health Care Professionals towards ADRs reporting in South- South Zone of Nigeria

\begin{tabular}{lccccc}
\hline Items & $\begin{array}{c}\text { All HCPs } \\
\mathbf{n}=796\end{array}$ & $\begin{array}{c}\text { Doctors } \\
\mathbf{n = 3 7 3}\end{array}$ & $\begin{array}{c}\text { Nurses, } \\
\mathbf{n = 3 4 3}\end{array}$ & $\begin{array}{c}\text { Pharmacists } \\
\mathbf{n = 8 0}\end{array}$ & P-value* $^{*}$ \\
\hline $\begin{array}{l}\text { Belief that all ADRs should } \\
\text { be reported }\end{array}$ & $735(92.3)$ & $343(92.0)$ & $316(92.1)$ & $76(95.0)$ & 0.729 \\
$\begin{array}{l}\text { Professional obligation to } \\
\text { report }\end{array}$ & $733(92.1)$ & $352(94.4)$ & $302(88.0)$ & $79(98.8)$ & 0.001 \\
$\begin{array}{l}\text { ADRs reporting does not put } \\
\text { career at risk }\end{array}$ & $733(92.1)$ & $353(94.6)$ & $305(88.9)$ & $75(93.8)$ & 0.016 \\
$\begin{array}{l}\text { Reporting should be made } \\
\text { mandatory }\end{array}$ & $721(90.6)$ & $340(91.2)$ & $308(89.8)$ & $73(91.3)$ & 0.824 \\
$\begin{array}{l}\text { ADRs reporting should not } \\
\text { be for publishing only }\end{array}$ & $714(89.7)$ & $344(92.2)$ & $297(86.6)$ & $73(91.3)$ & 0.040 \\
$\begin{array}{l}\text { Not expecting to receive } \\
\text { incentives for reporting }\end{array}$ & $606(76.1)$ & $318(85.3)$ & $235(68.5)$ & $53(66.3)$ & $<0.001$ \\
$\begin{array}{l}\text { Reporting when unsure if } \\
\text { ADRs has occurred }\end{array}$ & $584(73.4)$ & $271(72.7)$ & $248(72.3)$ & $65(81.3)$ & 0.249 \\
$\begin{array}{l}\text { Belief of reporting when not } \\
\text { sure it will make a difference }\end{array}$ & $552(69.3)$ & $259(69.4)$ & $232(67.6)$ & $61(76.3)$ & 0.318 \\
$\begin{array}{l}\text { No difficulty in determining } \\
\text { if an ADRs had occurred }\end{array}$ & $453(56.9)$ & $187(50.1)$ & $219(63.8)$ & $47(58.8)$ & 0.001 \\
\hline
\end{tabular}

ADRs: Adverse Drug Reactions, *p value from Pearson Chi square test and Fisher's exact test,

HCPs: Health Care Professionals

Table 4: ADRs reporting practices among HCPs in the South-South Zone of Nigeria

\begin{tabular}{lccccc}
\hline & $\begin{array}{c}\text { All HCPs } \\
\mathrm{n}=796\end{array}$ & $\begin{array}{c}\text { Doctors, } \\
\mathrm{n}=373\end{array}$ & $\begin{array}{c}\text { Nurses, } \\
\mathrm{n}=343\end{array}$ & $\begin{array}{c}\text { Pharmacists, } \\
\mathrm{n}=80\end{array}$ & p-value \\
\hline Ever observed an ADRs & $658(82.7)$ & $320(85.8)$ & $270(78.7)$ & $68(85)$ & 0.041 \\
Ever reported an ADRs* & $241(30.3)$ & $71(19.4)$ & $126(38.2)$ & $44(57.1)$ & $<0.001$ \\
Main mode of reporting, & & & & \\
(n=241) & & & & & \\
- Yellow form & $97(40.2)$ & $41(57.7)$ & $13(10.3)$ & $43(97.7)$ & $<0.001$ \\
- Case note & $53(21.7)$ & $25(35.2)$ & $26(20.6)$ & $2(4.5)$ & $<0.001$ \\
- Ward report book & $88(35.7)$ & $2(2.8)$ & $84(66.7)$ & $1(2.3)$ & $<0.001$ \\
Training in ADRs reporting & $126(15.8)$ & $40(10.7)$ & $40(11.7)$ & $46(57.5)$ & $<0.001$ \\
\hline
\end{tabular}

HCPs: Health Care Professionals, ADRs: Adverse Drug Reactions. p value from Fishers exact test * documented or reported an ADR. 
Three hundred and eighteen (39.9\%) of all respondents found it difficult to determine if an ADR had occurred. Of these, only $25 \%$ gave reasons for their difficulty: use of multiple medicines including herbal medicines by the patients and possibilities of drug-drug interactions (32.1\%), ADRs may mimic the constitutional symptoms of the disease $(25.9 \%)$, patients not reporting ADRs $(27.2 \%)$, lack training in ADRs recognition, loss of a patient to follow up (4.9\%), inability to identify drug including difficulty in establishing causality, uncertainty about drug history (9.9\%) [Multiple responses were accepted].

Very few respondents 63 (7.9\%) felt reporting ADRs puts their careers at risk and only a few gave the following reasons for their choice: risk of punitive measures against the reporter (9.5\%), perception of the HCPs as incompetent/negligent $(6.3 \%)$, others $(7.9 \%)$ include fear of litigation, the inter-professional rivalry between HCPs, liability of the pharmaceutical company and violent reactions from relations if death occurs.

\section{The practice of Pharmacovigilance by HCPs in} South-south Nigeria

Six hundred and fifty-eight HCPs $(82.7 \%)$ stated that they had previously observed ADRs. However, only $241(30.3 \%)$ had ever documented or reported ADRs using any method of reporting. More pharmacists $(57.1 \%)$ had documented or reported ADRs than other HCPs $(p<0.001)$. Of those that had documented or reported, different modalities were used; 97 (40.2\%) used the national ADRs reporting form, 87 (36.1\%) used the ward report book, 53 (22 $\%)$ used the patients' case record, and $14.3 \%$ reported verbally to the doctor, pharmacist or senior colleague. Three $(1.2 \%)$ respondents published a case report, while others (1.2\%) used the patient's treatment sheet, filled a critical event form, and filled the pharmaceutical care daily worksheet. Nurses were less likely to report with the national ADR reporting form (Table 4).

Among the 97 respondents who had reported ADRs using the national ADRs reporting forms, $60.8 \%$ found it easy accessing the ADRs forms from various locations such as the clinics and wards (37.3 $\%)$, and drug information centres (11.9\%). However, $38.2 \%$ found accessing the ADRs forms difficult mostly due to poor accessibility at the point of use $(44.1 \%)$, poor awareness of the location of the pharmacovigilance centre or committee to obtain the form $(14.7 \%)$.

Regarding use of the forms, 79 (81.4\%) found reporting with the national ADRs form easy. However, $9.2 \%$ of respondents found the form being too time-consuming, having too many questions and lacking required information. The process of returning the form was very easy or easy for $55.6 \%$ of respondents and the filled forms were mostly sent to the local Pharmacovigilance centre as reported by $69.1 \%$ of the respondents (Responses had been synthesised and multiple responses were accepted).

\section{Training and Factors to improve ADR reporting}

Analysing the HCPs who had reported an ADR using the national ADRs form, the following variables were found to have a significant association with reporting: $g e n d e r\left(?^{2}=9.8, p=0.002\right)$ cadre of HCPs- $\left(?^{2}=152.2, \mathrm{p}=<0.001\right)$, and previous training on ADRs reporting $\left(?^{2}=67.3, p=<0.001\right)$.

Furthermore, when requested to suggest ways of improving ADRs reports in their centres, the respondents proffered the following solutions; increased awareness and education on ADRs reporting $(278,34.9 \%)$, improve accessibility to the reporting forms $(38,4.8 \%)$, and streamlining the process of returning ADRs forms (16, $2.0 \%)$.

\section{DISCUSSION}

This study assessed the KAP of HCPs in the SouthSouth geo-political zone of Nigeria regarding pharmacovigilance. The study shows that documenting and reporting of ADRs is still inadequate and fewer HCPs used the national ADRs reporting form. A similar finding was reported in studies in other parts of Nigeria, where very few reporters have used the national ADRs form in reporting ADRs. ${ }^{9-11}$ The poor utilization of the ADRs reporting form in this study was attributed to poor awareness of the form, difficulty in accessing the form, lack of time, poor awareness of the local pharmacovigilance committee as was also observed in similar studies. ${ }^{9-11}$ The developing pharmacovigilance system in Nigeria with limited infrastructures and insufficient engagement of the 
health care facilities could have also contributed to this result. A similar trend of poor reporting of ADRs was also observed in some African countries with developing pharmacovigilance systems and also in countries outside Africa with developed pharmacovigilance systems. ${ }^{26-28}$ This suggests that there is a need for the enlightenment of the HCPs regarding pharmacovigilance regardless of the status of the pharmacovigilance system.

This study shows that the HCPs had inadequate knowledge regarding certain types of ADR such as delayed ADRs, end of use ADRs, ADRs resulting from herbal medicine use, medication errors, drug dependence, drug misuse, and abuse as seen in another study. ${ }^{13}$ The proportion of correct answers was lowest in nurses compared with other HCPs. Under-recognition of ADRs is a significant contributor to under-reporting and may consequently lead to underestimation of data with poor quantification of the attendant risks. This is noteworthy in a setting where medicine safety is still poorly attended to. Again, the HCPs inadequate knowledge that medication errors ought to be reported could be due to fear of litigation or penalties as seen in a previous study that showed that the Nigerian HCPs were largely unwilling to report medication errors. ${ }^{29}$ There is a need to sensitize the professionals towards the identification of various types of ADRs and product concerns to heighten their index of suspicion.

There was a good knowledge of the HCPs that can report ADRs, Respondents in this study felt that traditional medicine practitioners and patent medicine dealers could report ADRs due to the high patronage they enjoy, as this may improve patient safety. However, there is a need for a critical assessment of the reports that may emanate from these quarters to ascertain the quality of the report. ${ }^{8}$ These, as well as ongoing in-country patient reporting ${ }^{30}$ will require development of systematic reporting modes.

A good proportion of the respondents had awareness about the local pharmacovigilance and NPC but not the exact locations, this is similar to what was reported in another Nigerian study. ${ }^{13}$ This lack of knowledge of the exact location may delay reporting timelines and communication due to misdirected reports. There was generally a poor awareness of the South-South Zonal Centre. This may not be unrelated to the fact that the zonal centres were created just four years before our study and were yet to become fully operational due to logistical issues. Regionalisation of centres is meant to improve reports, ${ }^{31}$ therefore, it is hoped that more awareness campaigns would be carried out in the zone.

The limitations experienced by some of the respondents in processing the ADR form (difficulty in accessing and returning) may account for the few reports sent by the respondents. Other studies in Nigeria had also shown that HCPs were not sure of how to access and return the ADR form. ${ }^{9,13}$ This highlights a need to have regular monitoring and evaluation of the pharmacovigilance system to improve the reporting process and the quality of the reports. The routine use of pharmacovigilance indicators will enable the institution and the NPC improve the system. ${ }^{32}$

In this study, a high proportion of the HCPs had observed ADRs before but only a third had ever documented or reported it. The study showed that the nurses documented ADRs in case notes, ward report books than report with the ADRs form. This was seen also in other studies where the nurses also used ward report books. ${ }^{9,10}$. This may be due to the accessibility of the case notes and report books to the HCPs that made documentation easier in the case notes and report books. This documentation in report books and case notes may be responsible for the insufficient number of reports in the NPC database compared to what obtains in developed nations as these documented ADRs remain in the patients' case files and do not undergo causality assessment or provide information on that particular medicine. There is a need to address detection of ADRs from these sources as an avenue to increase the number of ADRs in the NPC's database while encouraging the HCPs to report using the national ADRs form. ${ }^{10,33}$

Attitudinal reasons are about the strongest determinants of ADRs underreporting, 6 thus, we investigated attitudinal factors contributing to poor reporting of ADRs in South-south Nigeria. The fear of litigation and punitive measures were important reasons that were attributed to poor reporting in 
this study as shown in other studies. ${ }^{34,35}$ This may be related to a general fear of disclosure of medicationrelated issues and poor understanding of the mechanisms of ADRs. The HCPs may have to be properly educated about the ethics and legal aspects involved in health care. It is noteworthy that most of the respondents do not expect incentives for reporting. This is an important factor that needs to be highlighted to encourage the HCPs that are interested in patient safety. Although a study had shown that incentives may improve reporting,'36 a resource-challenged setting like ours may be unable to meet such a goal. Again, the potential for abuse of such measure is high.

Previous training and the profession of the HCPs were associated with reporting using the national ADRs reporting. It was observed that pharmacists appeared to have better knowledge and reporting practices than the other cadres of HCPs, this may be due to the proximity of the drug information centres to their practice area as well as the possibility of previous training. ${ }^{10}$ Previous studies have proffered education of the HCPs as means of improving ADRs reporting. ${ }^{28,37}$ The present study has shown that emphasis needs to be laid on improving the knowledge of the HCPs regarding types of ADRs, and product concerns in pharmacovigilance.

In addition, the attitudinal problems identified in this study can be addressed during training. The performance of the pharmacists may be due to possible formal undergraduate training thus incorporation of pharmacovigilance and ADRs reporting into the undergraduate and postgraduate curricula of nurses and doctors may be necessary. ${ }^{38}$ Due to observed deficiencies in the pharmacovigilance systems in the hospitals, ${ }^{39}$ there is a need to entrench pharmacovigilance in the institution to improve access to ADRs form for reporting. This study has shown that the SouthSouth zone will require a multifaceted intervention to improve ADRs reporting with necessary institutional changes. The pharmacovigilance system in the teaching hospitals in the South-South zone appears to be in the developmental stages with the nurses being the least knowledgeable, the least reporting with the ADRs form, and the least with positive attitudes. This has some implications for future work in the region as increased emphasis will be needed to encourage nurses to embrace ADRs reporting. Incorporation of pharmacovigilance into the yearly continuous professional development courses may be a way of educating the HCPs.

A few limitations were encountered in this study. The study questionnaire utilised the yes, no or I don't know format which may have limited the choices of the HCPs in some areas investigated. However, there were open-ended questions that allowed for free comments regarding specific areas in the questionnaire. There is a possibility of recall bias and courtesy bias among the HCPs, which cannot be fully overcome in questionnaire-based studies.

\section{CONCLUSION}

In all, based on the information obtained from this study, it could be concluded that the HCPs in the South-South zone have a fair knowledge, positive attitude but inadequate reporting practices regarding pharmacovigilance. Training, awareness creation, and a general change in attitude especially among the nurses and improving the reporting processes at the various institutions are required to improve pharmacovigilance in the zone.

Conflicts of Interest: The authors state that there are no potential conflicts of interest regarding this work.

\section{Funding: The study was self-funded}

Authors' contribution: All authors contributed to the design, definition of intellectual context, data analysis, manuscript preparation and review. AOO did data collection.

Acknowledgements: The authors express their sincere gratitude to the Chief Medical Directors of the various institutions and to the Director General of the National Agency for Food Drug Administration and Control, (NAFDAC), the National Drug Safety Advisory Committee (NDSAC), the Director of the National Pharmacovigilance Centre and also to the respondents in all the Teaching Hospitals who participated in the study. 


\section{REFERENCES}

1. World Health Organization. The Importance of Pharmacovigilance, Safety Monitoring of Medicinal Products. Geneva: World Health Organisation; 2002.

2. Meyboom RH, Egberts AC, Gribnau FW, Hekster YA. Pharmacovigilance in perspective. Drug Saf.1999;21:429-47.

3. World Health Organization-Uppsala Monitoring Centre. Uppsala Reports: Mapping the herbal jungle. Uppsala,Sweden; 2018.

4. World Health Organization- Uppsala 15. Monitoring Centre. Uppsala reports 66. Uppsala Reports 66. Uppsala, Sweden; 2014.

5. Tandon VR, Mahajan V, Khajuria V, Gillani Z. Under-reporting of adverse drug reactions: a challenge for pharmacovigilance in India. Indian J Pharmacol. 2015;47:65-71.

6. Lopez-Gonzalez E, Herdeiro M, Figueiras A. Determinants of Under-reporting of adverse drug reactions- A systematic review. Drug Saf. 2009;32:19-31.

7. Sabblah G, Akweongo P, Darko D, Dodoo A, Sulley A. Adverse drug reaction reporting by doctors in a developing country: A case study from Ghana. Ghana Med J. 2014;48:189-93.

8. Olowofela A, Fourrier-Réglat A, Isah AO. Pharmacovigilance in Nigeria: An Overview. Pharmaceut Med. 2016;30:87-94.

9. Fadare J, Enwere O, Afolabi A, Chedi B, Musa A. Knowledge, Attitude and Practice of Adverse Drug Reaction Reporting among Healthcare Workers in a Tertiary Centre in Northern Nigeria. Trop J Pharm Res. 2011;10:235-42.

10. Ogundele S, Dawodu C, Ogunleye O. Adverse drug reaction reporting among healthcare workers at a Nigerian Tertiary Hospital: a comparative cross-sectional survey of health care professionals. Glob Res J Med Sci. 2012;2:32-7.

11. Chinenye JU, Michael OU. Health workers and hospital patients knowledge of Pharmacovigilance in Sokoto, North-West Nigeria. Niger J Pharm Sci. 2012;11:31-40.

12. Adisa R, Omitogun TI. Awareness, 22. knowledge, attitude and practice of adverse drug reaction reporting among health workers and patients in selected primary healthcare centres in Ibadan, southwestern Nigeria. BMC Health Serv Res. 2019;19:926.

13. Oshikoya KA, Awobusuyi JO. Perceptions of doctors to adverse drug reaction reporting in a teaching hospital in Lagos, Nigeria. BMC Clin Pharmacol. 2009;9:14.

14. Bello SO, Umar MT. Knowledge and attitudes of physicians relating to reporting of adverse drug reactions in Sokoto, NorthWestern Nigeria. Ann Afr Med. 2011;10:13-8.

Akhideno, Fasipe OJ, Isah AO. The incidence and prevalence of adverse drug reactions among medical inpatients in a Nigerian University Teaching Hospital. J Curr Res Sci Med. 2018;4:86.

16. Adedapo ADA, Adedeji WA, Adedapo IA, Adedapo KS. Cohort study on adverse drug reactions in adults admitted to the medical wards of a tertiary hospital in Nigeria: Prevalence, incidence, risk factors and fatality. Br J Clin Pharmacol. 2021;87:1878-89.

17. Akor, A.A., Ajiga EA AB. Knowledge , perception and determinants of utilization of pharmacovigilance services among healthcare practitioners in Abuja. Res J Heal Sci. 2018;6:133-40.

Ohaju-Obodo JO, Iribhogbe OI. Extent of pharmacovigilance among resident doctors in Edo and Lagos states of Nigeria. Pharmacoepidemiol Drug Saf. 2010;19:191-5.

19. National Pharmacovigilance Centre (NPC) NAFDAC. Safety of medicines in Nigeria: a guide for detecting and reporting adverse drug reactions. NAFDAC-NPC-NIG- . A buja, Nigeria.: N a tional Pharmacovigilance Centre (NPC), NAFDAC,; 2004.p. I.

20. National Population Commission and National Bureau of Statistics. National Population Estimates. Abuja, Nigeria; 2016.

Centers for Disease Control and Prevention and US Department of Health and Human Services. CDC - Epi Info ${ }^{\mathrm{TM}}$ 7. 2008.

Figueiras A, Herdeiro MT, Polónia J, GestalOtero J. An educational intervention to improve physician reporting of adverse 
drug reactions: A cluster-randomized controlled trial. JAMA. 2006;296:1086-93.

23. Belton KJ, Lewis SC, Payne S, Rawlins MD, Wood SM. Attitudinal survey of adverse 32 drug reaction reporting by medical practitioners in the United Kingdom. Br J Clin Pharmacol. 1995;39:223-6.

24. Kharkar M, Bowalekar S. Knowledge, attitude and perception/practices (KAP) of 33. medical practitioners in India towards adverse drug reaction (ADR) reporting. Perspect Clin Res. 2012;3:90.

25. World Health Organization. International drug monitoring: the role of national centres. Technical Report Series. Geneva, Switzerland; 1972.

26. Olsson S, Pal SN, Stergachis A, Couper M. Pharmacovigilance activities in 55 low-and middle-income countries: A questionnairebased analysis. Drug Saf. 2010;33:689-703.

27. Isah AO, Pal SN, Olsson S, Dodoo A, Bencheikh RS. Specific features of medicines safety and pharmacovigilance in Africa. Ther Adv Drug Saf. 2012;3:25-34.

28. Ali Saleh H, Figueras A, Fourrier-Réglat A. 36. Knowledge, Attitude and Practice of Health Professionals Towards Adverse Drug Reactions Reporting. Eur J Pharm Med Res. 37. 2016;3:12-21.

29. Ogunleye OO, Oreagba IA, Falade C, Isah A, Enwere O, Olayemi S, et al. Medication errors among health professionals in Nigeria: A national survey. Int J Risk Saf Med. 2016;28:77-91.

30. Ogar CK, Ibrahim A, Osakwe AI, Jajere F, Kigbu-Adekunle AA, Alonge $\mathrm{K}$, et al. Pharmacovigilance Rapid Alert System for Consumer Reporting (PRASCOR): A look at its quantitative contribution to spontaneous reporting in Nigeria from August 2012 to February 2017. Pharmaceut Med. 2018;32:131-41.

31. Begaud B. Pharmacovigilance in France: A Decentralized Approach. In: Strom BL, Velo
G, editors. Drug Epidemiology and PostMarketing Surveillance. Boston, MA: Springer US; 1992. p. 39-42.

World Health Organization. WHO pharmacovigilance indicators: A practical manual for the assessment of pharmacovigilance systems. WHO. Geneva: World Health Organisation; 2015.1-73 p.

Santosh K, Tragulpiankit P, Edwards IR, Gorsanan S. Knowledge about adverse drug reactions reporting among healthcare professionals in Nepal. Int J Risk Saf Med. 2013;25:1-16.

34. Santosh KC, Tragulpiankit P, Gorsanan S, Edwards IR. Attitudes among healthcare professionals to the reporting of adverse drug reactions in Nepal. BMC Pharmacol Toxicol. 2013;14:16.

35. Okechukwu R, Odinduka S, Ele G, Okonta M. Awareness, attitude and practiceof pharmacovigilance among health care professionals in Nigeria: Survey in a Teaching Hospital,. Int J Hosp Res. 2013;2:99-108.

Feely J, Moriarty S, O'Connor P. Stimulating reporting of adverse drug reactions by using a fee. Br Med J. 1990;300:22-3.

Osakwe A, Oreagba I, Adewunmi AJ, Adekoya A, Fajolu I. Impact of training on Nigerian healthcare professionals' knowledge and practice of pharmacovigilance. Int J Risk Saf Med. 2013;25:219-27.

38. Beckmann J, Hagemann U, Bahri P, Bate A, Boyd IW, Dal Pan GJ, et al. Teaching Pharmacovigilance: the WHO-ISoP Core Elements of a Comprehensive Modular Curriculum. Drug Saf. 2014;37:743-59.

39. Opadeyi AO, Fourrier-Réglat A, Isah AO. A ssessment of the state of pharmacovigilance in the South-South zone of Nigeria using WHO pharmacovigilance indicators. BMC Pharmacol Toxicol. 2018;19:27.

Cite this article as: Opadeyi AO, Fourrier-Réglat A, Isah AO. Knowledge, Attitude and Practice of Health Care Professionals Regarding Pharmacovigilance in South-South Nigeria. KJMS 2021; 15(1): 54 - 64. 